\title{
Which is a Better Predictor of Job Performance: Job Satisfaction or Life Satisfaction?
}

\author{
Michelle D. Jones \\ Providence College
}

\begin{abstract}
Will people who are happy with their jobs exhibit superior job performance? Researchers have examined the "happy worker is a productive worker" postulation for decades and concluded the relationship between job satisfaction and job performance is not as strong as one would expect. The current research investigates possible explanations, including operationalizations of the satisfaction and performance variables. Using information from 87 respondents and their supervisors, the addition of life satisfaction and organizational citizenship behavior to the model was tested. Results moderately supported the addition of life satisfaction to increase our ability to predict inand extra-role job performance.
\end{abstract}

\section{Review of Relevant Literature}

The speculation that job satisfaction is related to performance dates back to the early days of the field of Industrial/Organizational Psychology (e.g., Kornhauser \& Sharp, 1932). Throughout the years, organizational theorists have advanced several viewpoints regarding the nature of the satisfaction-performance relationship: (1) satisfaction causes performance; (2) performance causes satisfaction; (3) the satisfaction-performance relationship is moderated by a number of other variables; or (4) both are caused by an exogenous variable. Some moderators examined in past research include the contingency of rewards (e.g., Jacobs \& Solomon, 1977; Lawler, 1973), situational constraints (e.g., Bhagat, 1982; Herman, 1973), self-esteem (e.g., Jacobs \& Solomon, 1977; Lopez, 1982), pressures for production (Triandis, 1959), and reciprocity norms (Organ, 1977). Each of these proposed relationships has been investigated by numerous researchers. Yet there remains no clear consensus on which explanation is most valid across all settings or the circumstances in which each explanation is most valid.

Furthermore, the majority of empirical findings published on this topic point to the apparent conclusion that the relationship between satisfaction and performance is weak at best. Nonetheless, many researchers continue to pursue the investigation of this relationship largely because of the apparently commonsensical link between the two variables. While most people associated with the human relations movement focused on improving performance through satisfying employees' needs, research results contradicted this underlying assumption (e.g., Katz, Maccoby, Gurin, \& Floor, 1951; Katz, Maccoby, \& Morse, 1950). These researchers found no differences in satisfaction between high and low performance groups, and, in some cases, concluded that those with lower performance levels reported higher satisfaction. Brayfield and Crocket (1955) reviewed existing literature and profoundly changed the nature of investigations regarding this relationship when they concluded that there was little evidence of a 
connection between employee attitudes and their performance. Many researchers now consider the relationship between job satisfaction and performance among employees to be what Chapman and Chapman (1969) called an "illusory correlation" - a perceived relationship between two variables that we logically or intuitively think should interrelate, but, in fact, do not.

\section{Previous Research Findings}

Research examining the relationship between satisfaction and performance has been conducted since at least as early as 1945 (e.g., Brody, 1945), and the methodology utilized has varied greatly. Some researchers used established scales to measure job satisfaction, while some developed their own. Some used self-report ratings to assess performance, while others used peer or supervisor ratings. Populations studied include diverse groups, such as college students, homemakers, public employees, bus drivers, engineers, salespeople, military personnel, physicians, and business school faculty members (cf. laffaldano \& Muchinsky, 1985). Estimated effect sizes range from $r=-.39$ (e.g., Podsakoff, Todor, \& Skov, 1982) to $r=.86$ (Lawshe \& Nagle, 1953).

In a landmark book that is still widely cited today, Vroom (1964) analyzed 20 studies conducted between 1949 and 1963 that examined the relationship between satisfaction and performance and reported a median correlation of $r=.14$. This weak positive average correlation was one of the first substantial indications that the relationship between these two variables was not as strong as was previously believed.

Since Vroom's results were published, others have attempted to replicate his findings. Partly in response to criticisms of Vroom's (1964) research on this topic, Petty and his colleagues (1984) used more sophisticated meta-analysis techniques to replicate Vroom's finding. Their meta-analysis contained 15 studies used by Vroom (1964) and an additional 20 studies published between 1967 and 1982 that utilize individual-level measures of performance and satisfaction. When the researchers excluded the studies included by Vroom (1964), they calculated an estimated effect size of .23 based on the remaining 20 studies with a combined sample size of 3,140 respondents.

A more recent meta-analysis investigating the relationship between job satisfaction and performance was conducted by laffaldano and Muchinsky (1985). This research investigated the strength of the relationship and attempted to draw a robust conclusion other researchers would not dispute by subjecting findings regarding the relationship between performance and satisfaction to more thorough meta-analytic procedures. Their research included 74 empirical studies published in 70 articles with a total sample size of 12,192 subjects and 217 effect sizes. In a finding surprisingly similar to Vroom's (1964), they concluded that the estimated true correlation between performance and all types of satisfaction measures after correcting for the effects of sampling error and attenuation due to unreliable measurement of both satisfaction and performance is $r=$ .17 .

As can be seen in Table 1, which summarizes the findings from these three metaanalyses, all three studies came to a very similar conclusion regarding the estimated strength of the relationship between job satisfaction and job performance. In aggregate, 
the conclusions drawn by these researchers, and many others, substantiate the presence of a positive, but very weak, relationship between job satisfaction and job performance.

Table 1:

Estimated Effect Sizes for the Satisfaction-Performance Relationship at the Individual Level of Analysis from Three Meta-Analytic Reviews

\begin{tabular}{|c|c|c|c|c|c|}
\hline Study & $\begin{array}{c}\text { Estimated } \\
\text { Effect Size }\end{array}$ & $\begin{array}{c}\frac{\# \text { of }}{\text { Studies }} \\
\text { Included }\end{array}$ & $\begin{array}{c}\frac{\text { Level of }}{\text { Analysis }} \\
\text { Vroom (1964) }\end{array}$ & $\begin{array}{c}\text { Total } \\
\mathbf{N}\end{array}$ & $\begin{array}{c}\frac{95 \%}{\text { Confidence }} \\
\text { Interval* }\end{array}$ \\
\hline $\begin{array}{c}\text { Petty, McGee, \& Cavender } \\
(1984)\end{array}$ & $r=.23$ & 20 & Individual & 6,372 & .205 to .255 \\
\hline $\begin{array}{c}\text { Iaffaldano \& Muchinsky } \\
(1985)\end{array}$ & $r=.17$ & 74 & Individual & $\begin{array}{c}12,19 \\
2\end{array}$ & .152 to .188 \\
\hline
\end{tabular}

*NOTE: Confidence intervals calculated using total sample size $(\mathrm{N})$

\section{Proposed Explanations for the Satisfaction-Performance Relationship}

If one accepts the conclusion evidenced by researchers such as Vroom (1964) and laffaldano and Muchinsky (1985), it becomes important to seek an accurate explanation for this apparent lack of relationship. In the following section, several explanations for the findings pertaining to the relationship between these two variables are discussed. From this discussion, several key empirical hypotheses are derived, which will be tested in the current study.

\section{Operationalization of satisfaction}

Regarding Vroom's (1964) and laffaldano and Muchinsky's (1985) conclusions that there is a weak relationship between job satisfaction and performance, Wright and Cropanzano (2000) proposed "this relegation may be premature" (p. 85). They suggested the observed relationship between these two variables is not strong owing to a flaw in the manner in which satisfaction has been operationalized. Rather than operationalize this variable using a narrow measure, such as job satisfaction, Wright and Cropanzano proposed using a more comprehensive measure of happiness which captures satisfaction with various aspects of life. Indeed, when they used a measure of happiness instead of job satisfaction, they found a stronger relationship with performance $(r=.32)$. Similarly, Staw, Sutton, and Pelled (1994) analyzed data collected through the University of Michigan's Survey Research Center and found employee positive emotion was significantly related to work achievement in the form of supervisor ratings of performance $(r=.16)$ and pay $(r=.24)$.

While the theoretical basis for examining the relationship between life satisfaction and job performance appears sound, replication of findings such as these is necessary to strengthen our confidence in these conclusions and correct for any possible sampling errors. In particular, replication of the study by Wright and Cropanzano (2000) would be beneficial because these researchers based their conclusions on a small sample $(n=$ 
47) of a specialized group of employees (e.g., human service workers), used only an affective measure of well-being, and used a single item to assess the supervisor rating of job performance. In Staw et al.'s (1994) work, positive emotion was assessed using multiple sources (e.g., self-report and observer-report), however, the majority of the items focused on affective reports of signs of depression. In addition, while the researchers used supervisor evaluations to assess job performance, they experienced a very large drop-out rate of supervisors between time 1 and time 2 of their data collection process. Thus they were able to use data for only 60 employees to generate their estimates of the effect size. The current study is designed, in part, to test the theoretical proposition underlying studies such as these, namely, that life satisfaction (a.k.a. happiness) makes an important contribution to the prediction of job performance beyond that of job satisfaction.

\section{Operationalization of performance}

Several researchers have suggested the reason strong consistent results for the relationship between job satisfaction and performance have not been found is attributable to the manner in which performance is measured (e.g., Fisher, 1980; Organ, 1977). Specifically, they argued that performance has typically been measured in a narrow manner, which focuses on the degree to which an employee reaches either a quantity requirement or satisfies some preconceived standard for effective behavior (i.e., in-role performance). They advocate that, instead, performance should be conceptualized as not only a satisfaction of preconceived requirements, but should also include the performance of "spontaneous and innovative behavior," which Kahn and Katz (1960) felt was important to organizational effectiveness.

Kopelman, Brief, and Guzzo (1990) suggested three categories of pertinent behaviors for measuring organizational effectiveness: (1) attachment - attending to and staying in the organization; (2) performance - job-related tasks and activities comprising of the employee's formal organizational role; and (3) citizenship - cooperation and collaborative efforts. Part of the argument for using organizational-level measures of performance, instead of individual-level measures, is that individual performance may be constrained or facilitated by situational factors that can confound the relationship, such as budgetary support, time availability, job related information, or individual factors (ability, effort, or personality). Furthermore, several researchers have pointed out that most performance measures are restricted in range because of organizational attempts to constrain the work behavior and performance of employees (e.g., Johns, 1991; Staw, 1984). It is possible that employees experiencing dissatisfaction at work will react in ways other than lower performance that will not be observed in traditional studies of the satisfaction-performance relationships, such as filing a grievance, attempting to improve their performance, or asking for a transfer (Locke \& Latham, 1984).

Specifically, Fisher (1980) suggested that outcomes such as attendance, predictability, compliance, following of rules, cooperation, drug use, sabotage, and so forth also be included in the measurement of individual organizational performance. Similarly, Organ (1988) proposed that job performance should also contain a measure of the extent to which employees engage in organizational citizenship behaviors (OCBs), which he defined as behaviors which are (1) discretionary; (2) not directly or explicitly recognized 
by the formal reward system; and (3) in the aggregate, promote the effective functioning of the organization. Organ's definition of OCB goes far beyond the typical measure of job performance and measures the following additional factors: altruism, courtesy, sportsmanship, conscientiousness and civic virtue.

At the time Organ (1988) introduced this concept, he declared that research suggests "OCB and job satisfaction are bound together in a robust relationship." The first two empirical studies which examined the relationship between job satisfaction and OCB did, indeed, support this proposition that the correlation between satisfaction and organizational citizenship behavior was stronger than the correlations between satisfaction and performance published in previous studies (Bateman \& Organ, 1983; Smith, Organ, \& Near, 1983). Since that time, more than 50 studies have been published that investigate at least one of the five dimensions of OCB and its relation to job satisfaction. In a meta-analysis of 55 studies in this area, Organ and Ryan (1995) calculated average effect sizes for the five components of OCB. While most of the studies they examined included only measures of altruism and compliance, there were five studies that reported results for the other three aspects of OCB; however, these findings are less conclusive.

Overall, their findings support the conclusion that there is a robust relationship between satisfaction and OCB and that this relationship is, in fact, stronger than the relationship between satisfaction and in-role performance $(r=.24$ for altruism; $r=.22$ for compliance; $r=.24$ for courtesy, $r=.21$ for civic virtue; $r=.28$ for sportsmanship). The uncorrected estimated effect sizes for the relationships between satisfaction and these five measures of OCB exceed the uncorrected estimate calculated by laffaldano and Muchinsky (1985); moreover, the 95\% confidence intervals for these findings (.20 to .27 for altruism, .18 to .25 for compliance, .20 to .29 for courtesy, .16 to .26 for civic virtue, and .23 to .32 for sportsmanship) do not overlap with the $95 \%$ confidence interval for laffaldano and Muchinsky's uncorrected estimate (.123 to .169), with the exception of a slight overlap with the confidence interval for civic virtue. One could argue, however, that while these effect sizes are larger than those reported by Vroom (1964) and laffaldano and Muchinsky (1985), they do not significantly differ from that reported by Petty et al. (1984) ( $r=.23$ ). Organ and Ryan (1995), however, feel their results can be more accurately compared to the effect size estimate reported by laffaldano and Muchinsky (1985) because their finding is considered more robust due to the fact that their research not only covered a longer time period, but also included a considerably larger number of respondents $(N=12,192)$ than did Petty et al. $(1984)(N=3,140)$.

In addition, Organ and Ryan (1995) calculated an average correlation of $r=.38$ when all measures of OCB across all studies were collapsed and treated as an overall measure of the variable. In sum, they conclude their research provides support for the hypothesis that measures of OCB would be more related to satisfaction than would in-role job performance, but add the caveat that these findings are likely to hold up better for nonmanagerial, nonprofessional employees due to the fact that most research related to OCBs is conducted on these types of samples. 


\section{Relationship Between Job Satisfaction and Life Satisfaction}

As discussed previously, there is empirical support for the idea that if one measures overall life satisfaction (i.e. happiness or overall well-being), rather than job satisfaction, there is likely to be a stronger relationship with performance. Prior to investigating the relative strength of the relationship between life satisfaction and job performance, however, it is beneficial to examine the nature of the relationship between job satisfaction and life satisfaction. Most research investigating this relationship is correlational, thus preventing an accurate determination of the direction of causality in the relationship. Initially, in a meta-analysis containing 34 studies with a combined sample size of 19,811, Tait, Padgett, and Baldwin (1989) reported the estimated relationship between job satisfaction and life satisfaction to be .44 . To determine more accurately the direction of causality for this strong positive relationship, Judge and his colleagues (1993) used structural equation modeling and cross-lagged time designs. When looking at job and life satisfaction at the same point in time, Judge and Watanabe (1993) found evidence of a reciprocal relationship, but when lagged correlations were examined, there was evidence that life satisfaction was a significant predictor of job satisfaction five years later. A reasonable conclusion from this research would be that by making people happier with their lives overall, organizations are also increasing the job satisfaction of their employees and can, in turn, reap the benefits of having employees with high job satisfaction.

In contrast, using structural equation modeling, Judge and Hulin (1993) found support for the hypothesis that the relationship between job satisfaction and subjective wellbeing (e.g., happiness) is reciprocally causal. They summarized the implications of their findings by stating:

"to spend the majority of one's waking hours at a dissatisfying job appears to have a significant influence on the overall experienced well-being in one's life. Conversely, spending an equal amount of time at a satisfying and perhaps challenging and motivating job has a strong positive influence on one's subjective well-being. The role of work and work satisfaction in one's life should not be underestimated." (Judge \& Hulin, 1993, p. 414)

Their investigation showed that individuals with happy lives were much more likely to be satisfied with their jobs $(r=.41, p<.01$, one-tailed; $n=253)$ and vice versa $(r=.31, p<$ .01 , one-tailed; $n=253$ ). An examination of the difference between the chi-square values for the two models tested revealed that the two correlation coefficients were not significantly different, thus demonstrating that subjective well-being is not a significantly better predictor of job satisfaction than job satisfaction is of subjective well-being; subjective well-being is both a significant antecedent and a consequence of job satisfaction.

Overall, the findings of the Judge and Watanabe (1993) and Judge and Hulin (1993) studies suggest the strong positive relationship between job and life satisfaction would best be interpreted as a bi-directional path. The implication of findings such as these is that it is possible that an employee who is dissatisfied with his or her job, but very satisfied with his or her life, may perform well on the job. Conversely, an employee who 
is very satisfied with his or her job, but very dissatisfied with his or her life, may perform poorly on the job.

\section{Current Research Hypotheses}

In aggregate, the aforementioned research offers multiple potential explanations for the weak relationship between job satisfaction and job performance. Furthermore, it implies several suggestions for future research. While research exists that has investigated the superiority of broader measures of satisfaction and of broader measures of performance, no research exists that has attempted to examine both of these issues in a single empirical study.

Overall, the current research proposes the relationship between satisfaction and performance is stronger than the weak positive correlation found by researchers such as Vroom (1964) and laffaldano and Muchinsky (1985) and that this correlation can be found to be substantially larger when the operationalization of the two variables is broader than in past research.

Based on findings reviewed above from Wright and Cropanzano (2000) and Staw et al. (1994), it is expected that life satisfaction will be a better predictor of the outcome variables than is job satisfaction. The following hypotheses, therefore, are advanced:

Hypothesis 1: (a) The relationship between life satisfaction and in-role job performance will be stronger than the correlation between job satisfaction and in-role job performance. (b) The relationship between life satisfaction and OCB will be stronger than the relationship between job satisfaction and OCB. (c) The relationship between life satisfaction and the combined measure of performance (in-role performance and $\mathrm{OCB}$ ) will be stronger than the relationship between job satisfaction and the combined measure of performance.

Research by individuals such as Organ and Ryan (1995) offer preliminary evidence that there is a significant positive relationship between job satisfaction and organizational citizenship behavior; therefore, the following hypotheses regarding the relationships between the predictor variables and organizational citizenship behavior are extended:

Hypothesis 2: (a) The relationship between job satisfaction and OCB will be stronger than the relationship between job satisfaction and in-role job performance. (b) The relationship between life satisfaction and OCB will be stronger than the relationship between life satisfaction and in-role job performance. (c) The relationships between life satisfaction and job satisfaction and the combined measure of OCB and in-role job performance will exceed the relationships either satisfaction measure has with either individual performance assessment.

Vroom (1964) discussed the possibility that the association between job satisfaction and job performance is affected by other variables not controlled for by the researchers. Fairly convincing evidence has been offered by Tait et al. (1989), Judge and Watanabe (1993), and Judge and Hulin (1993) suggesting there is a strong positive relationship between life satisfaction and job 
satisfaction. To examine the possibility that life satisfaction operates as an intervening variable in the relationship between job satisfaction and performance, it must be determined that there is a relationship between life satisfaction and job satisfaction, therefore, the following hypothesis is proposed:

Hypothesis 3: There will be a positive relationship between life satisfaction and job satisfaction.

Table 2 summarizes the hypothesized relationships between the variables.

Table 2:

Anticipated Relative Strength of Hypothesized Relationships

\begin{tabular}{|c|c|c|}
\hline & $\begin{array}{c}\text { Job } \\
\text { Satisfaction }\end{array}$ & $\begin{array}{c}\text { Life } \\
\text { Satisfaction }\end{array}$ \\
\hline In-Role Performance & + & ++ \\
\hline Organizational Citizenship Behavior & ++ & +++ \\
\hline Combined Performance Measure & +++ & ++++ \\
\hline
\end{tabular}

\section{Method}

\section{Participants and Setting}

Using a convenience sampling strategy, a cross-sectional sample of 258 individuals was solicited through upper-division undergraduate evening management courses and evening MBA courses at a large Southern California university. Of the individuals solicited, 134 individuals volunteered to participate in the current study. At the time they volunteered, each participant was given two surveys - one to be completed by the participant and one to be completed by his or her supervisor (both surveys will be described in more detail below). Of the 134 survey packets distributed, 109 respondent surveys were completed and returned (response rate of 81.4\%) and 95 supervisor surveys were completed and returned (response rate of $70.9 \%$ ).

Identification numbers recorded on the two surveys were used to enable the researcher to match the participant's survey to the appropriate supervisor survey. Of the 134 individuals who volunteered to participate in the current study, complete data was received for 87 individuals (including both the respondent and supervisor surveys), representing an overall response rate of $64.9 \%$.

Approximately one fourth of the respondents were students enrolled in the MBA program ( $n=22 ; 25.29 \%$ ), slightly less than one fourth of the respondents were advanced undergraduate students $(n=20 ; 23.0 \%)$, and slightly less than one fourth of the respondents were "nontraditional" undergraduate students $(n=16 ; 19.1 \%)$, including returning students and students pursuing certificates in Business Administration. The remaining respondents consisted of "traditional" undergraduate 
students ( $n=28 ; 32.2 \%)$ and one non-student family member recruited by one of the respondents $(n=1 ; 1.1 \%)$. Almost half of the respondents were working at a full-time job at the time of the study $(n=39 ; 44.8 \%)$ and $37(42.5 \%)$ respondents reported having a part-time job as indicated in their self reports on the demographic portion of the questionnaire. Of the individuals who held full-time positions at the time of the study, the average length of time they had been working full-time was 9.8 years $(S D=6.86)$.

Respondents' reported occupation, job title, and employer industry were examined in combination with the researcher's personal knowledge about the respondents to determine how many respondents could be classified as having a "career track" job (as opposed to a temporary job) at the time of the study. Of the 75 respondents who 15 provided enough information to be able to clearly make this determination, 51 (68.1 were coded as having a "career track" job.

The average age of the respondents was 28.2 years $(S D=8.01)$ and the median $\bar{c}$ the respondents was 26 years. The average educational level of the respondents was 15.5 years $(S D=2.09)$ and almost one-third of respondents had already earned a BA or BS degree $(n=25 ; 31.3 \%)$. Slightly over half of the respondents were female $(n=48$; $58.5 \%)$ and overall, the respondents represent a very diverse cross-sectional sample. While the majority of the respondents were from the United States $(n=62 ; 77.5 \%)$, others reported being citizens of Germany, Hong Kong, Ghana, India, Jamaica, Nigeria, China, Taiwan, and Thailand. Of the respondents who reported their ethnicity in the demographic inventory, a large proportion indicated their ethnicity was Asian or Pacific Islander ( $n=40 ; 50.0 \%)$, and other ethnicities represented include African American, Hispanic, and Caucasian.

Respondents came from a wide variety of industries, including construction, manufacturing, finance and banking, education, health care, entertainment, and public administration. When asked to indicate the type of organization they work for, $28.8 \%$ ( $n$ $=23)$ of the respondents said they work for a large organization, and $21.3 \%(n=17)$ reported they work for a medium or small business. The next largest segment of respondents $(n=14 ; 17.5 \%)$ indicated they work for an educational institution. The remaining respondents designated they worked in a governmental or non-profit institution or were self-employed.

\section{Procedure}

Participants were asked to sign a consent form indicating their awareness that their participation in this study was voluntary and that they were free to withdraw at any time without consequences. In addition, respondents were given a questionnaire containing scales to measure the predictor variables and a separate sealed envelope containing the questionnaire to be completed by the respondent's supervisor which contains scales to measure the criterion variables. A letter describing the research aims and informing the supervisor that he or she was free to withdraw from participating in the study at any time was also contained in this envelope. Each supervisor was instructed to not complete the job performance measure in the presence of the individual being rated and to keep his or her responses confidential. 
Participants returned their completed survey to the researcher in person or in a provided self-addressed-stamped-envelope. The majority of supervisors returned completed research materials to the researcher in provided self-addressed stamped sealed envelopes, however, a few emailed their responses to the researcher.

To help ensure the validity of information collected, participants and their supervisors were guaranteed all information collected would remain confidential and would be viewed only by the researcher. Respondents were not permitted to see either the individual responses nor the aggregate performance ratings provided by their supervisors. Furthermore, supervisors were not allowed to see either the individual item responses or the overall scale scores provided by the respondents.

\section{$\underline{\text { Measures }}$}

Measures of job satisfaction and life satisfaction were administered in a single questionnaire completed by the respondent. The second questionnaire, which was completed by the respondent's supervisor, contained two distinct measures of job performance: a traditional measure which assesses the degree to which the employee meets the standards and/or requirement for his or her position (i.e., in-role performance) and a measure of organizational citizenship behavior (a.k.a. extra-role behavior).

\section{Satisfaction measures - job satisfaction.}

The Job Descriptive Index (JDI; Smith, Kendall, \& Hulin, 1969) was used to measure the respondent's level of job satisfaction. This scale is the most commonly used measure of job satisfaction and contains items to assess both the cognitive and affective components of this attitude. The JDI consists of five subscales with a total of 72 items that assess respondents' satisfaction with separate facets of their work environment: the work itself, their supervisor, pay, promotion opportunities, and coworkers. The scores on the five subscales can be summed to obtain an overall measure of job satisfaction. For each item presented, the respondent is asked to indicate whether the statement describes his or her current work environment by writing a " $Y$ " if it does and a " $\mathrm{N}$ " if it does not. If the respondent is unable to decide whether a given item accurately describes his or her work environment, he or she is instructed to write a "?" in the space provided. These scales are hand-scored by counting the number of responses in the "satisfied" direction provided by the respondent for each facet of job satisfaction (the "satisfied" response for each item can be found in Smith, et al., 1969). The entire scale was used: for three of the five facets (i.e., satisfaction with the work itself, with one's supervisor, and with one's coworkers), 18 items were presented for the respondent to evaluate. For the remaining two facets (i.e., satisfaction with pay and promotion opportunities), 9 items were presented. In the current study, the internal consistency of the overall measure of job satisfaction as reported on the JDI was $\alpha=$ .68 .

Satisfaction measures - life satisfaction.

Several scales to measure life satisfaction exist; however, the majority of them measure either the affective component or the cognitive component of this attitude. At the time of 
the study, none existed that measured both. To get a more complete measure of life satisfaction, therefore, the current research used two scales, one to evaluate the affective component - the Depression-Happiness Scale (McGreal \& Joseph, 1993) and one that assesses the cognitive component - the Satisfaction with Life Scale (Diener, Emmons, Larsen, \& Griffin, 1985). Scores on these two scales were summed to form an overall measure of life satisfaction.

The Satisfaction with Life Scale (SWLS) consists of five items to which participants respond by identifying the extent to which they agree or disagree with each statement on a 7-point Likert-type scale. Examples of items include: "In most ways my life is close to ideal," and "If I could live my life over, I would change almost nothing." Responses on each of the scale items were summed to obtain a respondent's score on this scale. The reliability coefficient for this scale in the current study is $\alpha=.76$.

The Depression-Happiness Scale has also been used by numerous researchers and consists of 25 items that express possible emotions an individual might feel in a typical week. Respondents are asked to indicate how often they felt the stated emotion in the past seven days on a 4-point Likert-type scale ranging from $0=$ "never" to $3=$ "often." Approximately half of the scale items are reverse-scored. Examples of items include: "I felt disappointed with myself (reverse-scored), "I felt satisfied with my life," and "I felt life was enjoyable." Responses on each of the scale items were summed to obtain a respondent's score on this scale. Cronbach's alpha for this scale in the current study is $\alpha=.87$. Sufficient convergent validity has been established for this scale by demonstrating substantial correlations with other happiness measures (e.g., $r=.47$ between the Depression-Happiness Scale and the Satisfaction with Life Scale; Lewis \& Joseph, 1995). When combined, the two scales assessing the two dimensions cognitive and affective - of life satisfaction had a internal consistency coefficient of $\alpha=$ .86 .

\section{Outcome measures.}

To get a broad measure of job performance, this variable was assessed utilizing two distinct measures, both completed by the individual's supervisor. Traditional job performance was measured using a four-item scale developed by Wright and Bonett (1993), which asks respondents to indicate the extent to which they agree or disagree that the presented statement describes the employee. The items are designed to tap four separate components of job performance (none of which is included in the measure of OCB): work facilitation, goal emphasis, support, and team building. Responses on each of the scale items were summed to obtain a respondent's score on this scale. Internal reliability of this scale in the current study was $\alpha=.81$.

A second supervisor-completed measure of job performance, organizational citizenship behavior, was measured using the abbreviated version of Bateman and Organ's (1983) Organizational Citizenship Behavior Scale. This scale consists of 30 items to which the respondent's supervisor indicates the extent to which he or she agrees with each statement presented on a 7-point Likert-type scale ranging from 7 = "agree completely" to 1 = "disagree completely." Examples of items include: "Helps others who have been absent," "Volunteers for tasks that are not required," and "Attends functions not 
required but that help company 'image."' Responses on each of the scale items were summed to obtain a respondent's score on this scale. The reliability coefficient for this scale in the current study is $\alpha=.89$.

Table 3:

Scale Descriptives

\begin{tabular}{|c|c|c|c|c|c|c|c|}
\hline$\frac{\text { Independent }}{\text { Variables }}$ & \# of & Alpha & $\underline{\mathbf{N}}$ & $\frac{\text { Mean }}{\text { Score }}$ & $\frac{\text { Possible }}{\underline{\text { Min. }}}$ & $\frac{\text { Possible }}{\text { Max. }}$ & $\frac{\text { Stan. }}{\text { Dev. }}$ \\
\hline $\begin{array}{l}\text { Satisfaction with work } \\
\text { itself* }\end{array}$ & 18 & $\mathrm{~N} / \mathrm{A}$ & 87 & 10.5 & 0 & 18 & $\overline{3.70}$ \\
\hline $\begin{array}{l}\text { Satisfaction with } \\
\text { supervisor* }\end{array}$ & 18 & N/A & 86 & 14.0 & 0 & 18 & 3.54 \\
\hline Satisfaction with pay* & 9 & $\mathrm{~N} / \mathrm{A}$ & 87 & 4.3 & 0 & 9 & 2.32 \\
\hline $\begin{array}{l}\text { Satisfaction with } \\
\text { coworkers* }^{*}\end{array}$ & 18 & $\mathrm{~N} / \mathrm{A}$ & 83 & 12.3 & 0 & 18 & 4.49 \\
\hline $\begin{array}{l}\text { Satisfaction with } \\
\text { promotions* }\end{array}$ & 9 & N/A & 85 & 4.0 & 0 & 9 & 2.74 \\
\hline $\begin{array}{l}\text { Overall job satisfaction } \\
\text { (JDI) }\end{array}$ & N/A & .6781 & 81 & 45.1 & 0 & 72 & 11.39 \\
\hline Satisfaction with Life Scale & 5 & .7614 & 87 & 22.8 & 5 & 35 & 5.68 \\
\hline $\begin{array}{l}\text { Depression-Happiness } \\
\text { Scale }\end{array}$ & 25 & .8656 & 86 & 51.0 & 0 & 75 & 10.11 \\
\hline $\begin{array}{l}\text { Life Satisfaction } \\
\text { (Combined) }\end{array}$ & 30 & .8622 & 86 & 73.9 & 5 & 110 & 13.80 \\
\hline $\begin{array}{l}\text { Dependent } \\
\text { Variables }\end{array}$ & items of & Alpha & $\underline{N}$ & $\frac{\text { Mean }}{\text { Score }}$ & $\frac{\text { Possible }}{\text { Min. }}$ & $\frac{\text { Possible }}{\frac{\text { Max. }}{\text { Score }}}$ & $\frac{\text { Stan. }}{\text { Dev. }}$ \\
\hline $\begin{array}{l}\text { Organizational Citizenship } \\
\text { Beh. }\end{array}$ & 30 & .8891 & 87 & 176.2 & 30 & 210 & 20.81 \\
\hline In-Role Job Performance & 4 & .8074 & 86 & 25.1 & 4 & 28 & 3.27 \\
\hline $\begin{array}{l}\text { Combined Job } \\
\text { Performance }\end{array}$ & 34 & .9049 & 86 & 201.7 & 34 & 238 & 23.02 \\
\hline
\end{tabular}

*NOTE: Reliability coefficients were not calculated for the subscales of the JDI due to the binary nature of the subscales 


\section{Results}

\section{Hypothesis Testing}

Correlational analyses were used to test the research hypotheses. Table 3 presents the obtained correlations between the hypothesized predictor and outcome variables.

Table 4:

Correlations Among Predictor and Criterion Variables

\begin{tabular}{|c|c|c|c|c|}
\hline Relationship & $\underline{R}$ & $\underline{\mathbf{N}}$ & Sig & $\begin{array}{c}\frac{95 \%}{\text { confidence }} \\
\text { interval }\end{array}$ \\
\hline Job Satisfaction and Life Satisfaction & .021 & 80 & .856 & -.203 to .243 \\
\hline \multicolumn{5}{|c|}{ 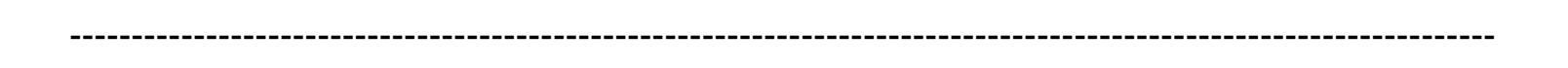 } \\
\hline Job Satisfaction and In-Role Job Performance & .137 & 80 & .225 & -.083 to .363 \\
\hline Job Satisfaction and OCB & .072 & 81 & .526 & -.150 to .294 \\
\hline Job Satisfaction and Combined Performance Measure & 077 & 80 & .499 & -.146 to .300 \\
\hline \multicolumn{5}{|c|}{ 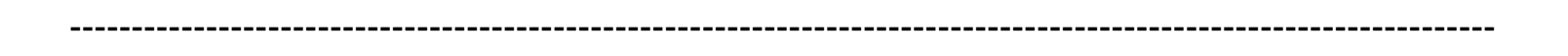 } \\
\hline Life Satisfaction and In-Role Job Performance & $.269^{*}$ & 85 & .013 & .054 to .486 \\
\hline Life Satisfaction and OCB & $.242^{*}$ & 86 & .025 & .032 to .462 \\
\hline Life Satisfaction and Combined Performance $\mathrm{N}$ & $.280^{\star \star}$ & 85 & .009 & .072 to .504 \\
\hline
\end{tabular}

$* p<.05$

${ }^{* *} p<.01$

Results support the first hypothesis postulating that the broader measure of satisfaction will lead to a stronger correlation between satisfaction and performance. Namely, the data revealed a stronger correlation between life satisfaction and the in-role job performance $(r=.269 ; p=.013)$ than between job satisfaction and in-role job performance $(r=.137 ; p=.225)$. Moreover, the relationship between life satisfaction and OCB $(r=.242 ; p=.025)$ was stronger than the relationship between job satisfaction and OCB $(r=.072 ; p=.526)$. Finally, the relationship between life satisfaction and the combined measure of job performance $(r=.280 ; p=.009)$ was stronger than the relationship between job satisfaction and the combined measure of performance $(r=$ $.077 ; p=.499)$. Further analyses, however, reveal no significant differences between the two correlations in each of these three sets $\left(z_{\text {calc }}=.869 ; z_{\text {calc }}=1.11 ; z_{\text {calc }}=1.33 ; p=\right.$ .05 , respectively).

The second research hypothesis proposes that the correlations between the predictor variables and organizational citizenship behavior will be stronger than the correlations between the predictor variables and in-role job performance and that the relationships with the combined measure of performance will exceed either of those. This hypothesis was partially supported in the current study. While neither was statistically significant 
and they did not differ significantly, the correlation between job satisfaction and in-role job performance $(r=.137 ; p=.225)$ was stronger in this sample than the correlation between job satisfaction and organizational citizenship behavior $(r=.072 ; p=.526)$. The same pattern was observed with regard to the correlations between life satisfaction and the outcome measures. Namely, the relationship between life satisfaction and inrole job performance $(r=.269 ; p=.013)$ was stronger in this sample than the relationship between life satisfaction and organizational citizenship behavior $(r=.242 ; p$ $=.025)$, however, these correlations did not differ statistically. While the correlation between job satisfaction and the combined measure of performance $(r=.077 ; p=.499)$ did not exceed the correlations between job satisfaction and the two performance measures individually, the correlation between life satisfaction and the combined measure of performance $(r=.280 ; p=.009)$ did exceed the correlations between life satisfaction and the two performance measures individually.

The third hypothesis proposes there will be a significant correlation between job satisfaction and life satisfaction. Contrary to expectations, the data did not show a significant correlation between these two variables $(r=.021 ; p=.856)$. Moreover, this lack of relationship and the lack of relationship between job satisfaction and the performance variables made the examination of the possibility of life satisfaction as an intervening variable not possible.

\section{Hierarchical Regression Analyses}

Hierarchical multiple regression analyses were performed to investigate the importance of life satisfaction in the prediction of in-role job performance, organizational citizenship behavior, and the combined performance measure above and beyond other predictors, specifically job satisfaction and organizational commitment. Examination of beta weights revealed life satisfaction did not significantly contribute to the prediction of in-role performance $(\beta=.169 ; p=.140)$ beyond job satisfaction and organizational commitment. Life satisfaction, however, came close to making a statistically significant contribution to the prediction of OCB $(\beta=.210 ; p=.064)$ beyond job satisfaction and organizational commitment and was a significant predictor of the combined measure of performance $(\beta=.239 ; p=.036)$ above and beyond the contributions of job satisfaction and organizational commitment.

\section{Examination of Possible Group Differences}

A series of five independent samples t-tests was conducted to examine the equality of means on the predictor and criterion variables among several subgroups in the sample. Variables tested include overall job satisfaction, life satisfaction (affective, cognitive, and combined measures), organizational citizenship behavior, in-role job performance, and the combined job performance measure. The first analysis revealed no significant differences between male and female respondents on any of the independent or dependent variables. The second analysis used a median split to determine whether age was a factor on which respondents differed in terms of their scores. This analysis revealed no significant difference between individuals younger than the median age (26 years) and individuals 26 years old or older. The third analysis revealed no significant differences between MBA and undergraduate students on any of the variables. The 
fourth analysis revealed no significant differences between professional/supervisory employees and nonprofessional/nonsupervisory employees on any of the variables. Based on these findings, it was concluded that there was sufficient evidence to justify excluding these variables from further analyses.

The fifth analysis investigated whether there were any significant differences between individuals who were classified as having a "career track" job and those who did not. Results revealed a significant difference between these two groups on two variables: life satisfaction $(t=2.67 ; p=.009 ; n=51$ career track employees and $n=23$ non-career track employees) and in-role job performance $(t=2.09 ; p=.041 ; n=50$ career track employees and $n=24$ non-career track employees). On the measure of life satisfaction (combined affective and cognitive components), individuals who had career track jobs reported significantly higher scores $(M=77.2)$ than did non-career track employees ( $M$ $=67.8$ ). This difference appears to be driven by a significant difference between the two groups on their scores on the Depression-Happiness Scale (affective measure of life satisfaction) ( $t=2.78 ; p=.007 ; n=51$ career track employees and $n=23$ non-career track employees), with career track employees reporting significantly higher scores $(M=$ 53.7 and $M=46.7$, respectively). These findings need to be interpreted with some caution because there is not a large enough sample of non-career track employees to accurately test for differences between the two groups.

\section{Discussion}

The current study examined knowledge gained from the addition of life satisfaction and organizational citizenship behavior to the satisfaction-job performance relationship. The results of the study support the addition of life satisfaction to the standard satisfactionperformance model to get a more complete understanding of the relationships between these variables.

\section{$\underline{\text { Key Findings }}$}

\section{$\underline{\text { Relationship between life satisfaction and performance }}$}

Organ's (1977) suggestion that satisfaction may not be related to performance not because no relationships exists, but because most research is measuring the wrong kind of performance was not supported in the current study. The results of the current study, however, provide evidence that researchers may have been measuring the wrong kind of satisfaction. In the current study, none of the relationships between job satisfaction and performance measures were strong or statistically significant, however, all relationships between life satisfaction and performance measures were statistically significant. Moreover, life satisfaction significantly contributed to the prediction of organizational citizenship behavior and the combined measure of OCB and in-role performance above and beyond the contributions of job satisfaction and organizational commitment. These findings are an important first step in establishing the relative importance of life satisfaction in the prediction of work-related performance and helps begin to answer the question posed by Moorman (1993) asking "is the construct of job satisfaction itself the most robust predictor of \{organizational\} citizenship?" (p. 774). 
In addition to testing new hypotheses, another goal of the current study was to replicate previous findings pertaining to the use of broader measures of satisfaction and performance to clarify the satisfaction-performance relationship. Due to the large sample size included $(N=12,192)$ in their analysis and the broad time period covered (1949 to 1983), laffaldano and Muchinsky's (1985) estimate of the correlation between job satisfaction and in-role job performance $(r=.17)$ appears to be the most robust to date. The current study yielded an effect size estimate of $r=.137$ for the job satisfaction-in-role job performance relationship. A comparison of these two effect sizes reveals no significant difference $\left(z_{c a l c}=.297 ; p=.05\right)$ between the two estimates.

Wright and Cropanzano (2000) reported a correlation of $r=.32$ between subjective wellbeing and in-role job performance, while the current study yielded an estimated effect size of $r=.269$. Comparison of these two correlations reveals no significant difference between the two estimates $\left(z_{\text {calc }}=.299\right)$. In addition, the current research yielded support for the hypothesis examining the added contribution of life satisfaction above and beyond that of job satisfaction to the prediction of job performance, thus extending this finding beyond that drawn by Wright and Cropanzano (2000).

\section{Addition of organizational citizenship behavior to performance assessment}

Results of the current study indicated the superiority of using a combined measure of inrole and extra-role performance to assess employee job performance. In particular, a broader measure which utilizes an assessment of the extent to which an employee fulfills his or her job requirements as well as an assessment of the extent to which he or she goes beyond those job requirements (engages in organizational citizenship behaviors) without receiving direct rewards for doing so, gives a more accurate picture of the employee's on-the-job performance.

In their meta-analysis of 55 studies, Organ and Ryan (1995) reported an estimated effect size of $r=.23$ for the relationship between job satisfaction and single-factor measures of OCB. The current study yielded a non-significant estimate of $r=.035$ for this relationship. Comparison of these two correlations reveals no significant difference between the two estimates $\left(z_{c a l c}=1.734 ; p=.05\right)$. A possible explanation for this substantial difference in the estimates of the effect size, however, may be that the nine studies included by Organ and Ryan (1995) in this analysis measured OCB as if it were a single performance factor rather than assessing it using a measure tapping the five components suggested by Organ (1988). Moreover, while some of the studies included reported an overall level of job satisfaction, others reported only satisfaction with various aspects of the job (e.g., pay, supervision, intrinsic, extrinsic), and these aspects were collapsed into a single correlation when no overall level of job satisfaction was reported. On the other hand, in the current study, the reported effect size estimate represents the relationship between an overall measure of job satisfaction and a measure assessing all five components of OCB. Thus, the difference between the finding in the current study and in Organ and Ryan's (1995) research may be due to variability in measurement techniques as opposed to a substantial difference in the underlying constructs. 
$\underline{\text { Relationship between life satisfaction and job satisfaction }}$

Tait et al. (1989) reported a correlation of $r=.44$ between job satisfaction and life satisfaction, while the current study produced a non-significant estimate of $r=.021$ for the relationship between these two variables. Comparison of these two estimates reveals a significant difference between these two correlations $\left(z_{\text {calc }}=3.95 ; p=.05\right)$. It is possible the current research resulted in different findings due to the measures used to assess job satisfaction and life satisfaction. In particular, Tait et al. (1989) included only effect sizes that were based on overall measures of job satisfaction as opposed to facet-specific measures. Thus, some studies that used the Job Descriptive Index (JDI) were eliminated, while others that provided an overall measure based on the JDI were included. The feasibility of this explanation cannot be determined with much accuracy, however, because Tait et al. (1989) did not include information regarding which measures were used to assess life satisfaction in any of the studies included in their meta-analysis.

\section{$\underline{\text { Implications for Managers and Organizations }}$}

Do the findings from this and other studies that conclude there is not a strong relationship between satisfaction and performance mean managers should no longer try to make their employees happy? Absolutely not. Regardless of the strength of the relationship between measures of satisfaction and measures of performance, job satisfaction has been shown to have links with other outcome variables, such as turnover and turnover intentions ( $r=-.27$ and $r=-.70$, respectively; Tett \& Meyer, 1993). In addition, researchers have linked higher levels of employee happiness with organizational outcomes such as more efficient, rapid, and creative problem solving techniques, more accurate information processing, and generation of favorable impressions with clients (Isen \& Means, 1983; Staw, et al., 1994).

Likewise, the current research suggests employees who are happy with their lives tend to be more productive in the workplace, both in terms of in-role and extra-role performance. Results from Koys' (2001) cross-lagged study among various locations of a regional restaurant chain support the idea that progressive HR strategies that encourage positive employee behavior, such as citizenship behavior, are related to good firm performance ( $r=.44$ for OCB at Time 1 and firm profit at Time 2).

\section{$\underline{\text { Potential Limitations }}$}

\section{Model specificity}

The theoretical model of satisfaction and performance presented in this study was a parsimonious attitude-behavior model. The limited number of predictor and criterion variables included in the model suggests that it may have been underspecified. For example, a range of organizational and personality variables, such as organizational culture, rewards systems, perceptions of justice, and job involvement, may have impacted the observed relationships between satisfaction and performance. Future research examining the relationship between life satisfaction and various types of 
performance would benefit from a more extensive model in which a wider range of personality and contextual variables are examined.

\section{$\underline{\text { Research design and direction of causality }}$}

Because of the cross-sectional nature of the study's research design, it was not possible to draw any causal conclusions regarding the relationships among the variables of interest. Specifically, the extent to which life satisfaction causes increased levels of in-role and extra-role performance cannot be demonstrated by the current study. As mentioned previously, several researchers have noted that the issue of causation regarding the relationship between job satisfaction and performance is debatable. Namely, although it is possible that increased satisfaction causes increased performance, it is also possible that high levels of performance cause increased satisfaction, that both variables are caused by a third exogenous variable, or that the relationship is moderated by a number of other variables.

\section{$\underline{\text { Sample }}$}

The generalizability of the findings from the present study must be considered in light of the nature of the sample and the sample size. The inclusion of respondents from a variety of organizational and industries, might introduce extraneous "noise" into the model. In future research, useful information can be gained from an investigation that examines the nature of the relationship between job satisfaction and performance among employees from various industries and types of businesses and controls for the variability introduced by this characteristic. Moreover, while tests were conducted to ensure career-track employees did not differ from employees with temporary jobs and that the graduate students did not differ from the undergraduate students, research in this area would benefit from replication of the findings with a sample drawn from an organizational setting.

\section{Restricted range}

The scores on both outcome measures in the current study - in-role job performance and organizational citizenship behavior - displayed distributions containing a restricted range such that there was no representation of poor performers included in the study. It is not unusual, however, for performance evaluation data to be restricted in range as a result of errors in leniency and central tendency. As mentioned previously, most performance measures are restricted in range because of organizational attempts to constrain the work behavior and performance of employees as well as the homogenizing effects of employee selection and training programs (e.g., Johns, 1991; Staw, 1984). Moreover, if an employee were performing at an unacceptable level, he or she would likely either remove himself or herself from the position or would be fired by his or her employer. Thus, it is not atypical to find this pattern of distributions in studies assessing job performance using supervisor ratings. Due to the restriction in range exhibited on the outcome measures of in-role job performance and organizational citizenship behavior, it is possible that the effect sizes calculated based on these distributions underestimate the true relationship. 


\section{Directions for Future Research}

While the current study establishes important first steps in the examination of the knowledge gained from the addition of broader measures of performance and satisfaction in our explanation of the nature of the satisfaction-performance relationship, additional research must be done before robust conclusions can be drawn. First, longitudinal studies must be conducted to determine the causal direction of the relationships involved. For example, some of the same questions posed regarding the relationship between job satisfaction and performance must be addressed. Namely, does life satisfaction cause higher levels of in-role and extra-role performance or does a person who performs at higher levels have a higher level of satisfaction with his or her life as a result of his or her job performance? Moreover, the causal direction of the relationship between life satisfaction and job satisfaction has received mixed results, therefore, additional research should focus on determining a more robust explanation for the direction of this relationship to enable practitioners to draw implications for organizational settings.

Second, with regard to the model tested in the current study, research in this area would benefit from the empirical examination of a more extensive model which includes a range of additional contextual and personality variables. Research designed to replicate the current model as well as research which expands upon the current model should utilize a triangulation of methods to determine the strength of these satisfactionperformance relationships. Expressly, both qualitative and quantitative methods should be used and, in addition to using supervisor ratings of performance, it would be beneficial to use actual performance ratings from various points in time to examine the causal direction and actual impact of various forms of satisfaction on performance.

\section{Conclusion}

The present study examined knowledge gained from the addition of life satisfaction and organizational citizenship behavior to the employee satisfaction-job performance relationship. Results demonstrate the addition of life satisfaction to the model increases our ability to predict employee performance on the job, both in terms of in-role and extra-role behaviors. The addition of organizational citizenship behavior to the measure of employee performance, however, did not substantially contribute to our understanding of the satisfaction-performance relationship. 


\section{References}

Bandura, A. (1977). Self-efficacy: Toward a unifying theory of behavioral change. Psychological Review, 84, 191-215.

Bateman, T. S., \& Organ, D. W. (1983). Job satisfaction and the good soldier: The relationship between affect and employee "citizenship." Academy of Management Journal, 26, 587-595.

Bhagat, R. S. (1982). Conditions under which stronger job performance-job satisfaction relationships may be observed: A closer look at two situational contingencies. Academy of Management Journal, 25, 772-789.

Brayfield, A. H., \& Crocket, W. H. (1955). Employee attitudes and employee performance. Psychological Bulletin, 52, 396-424.

Brody, M. (1945). The relationship between efficiency and job satisfaction. Unpublished master's thesis. New York: New York University.

Chapman, L. J., \& Chapman, J. P. (1969). Illusory correlation as an obstacle to the use of valid psychodiagnostic signs. Journal of Abnormal Psychology, 74, 271-280.

Diener, E., Emmons, R. A., Larsen, R. J., \& Griffin, S. (1985). The Satisfaction with Life Scale. Journal of Personality Assessment, 49, 71-75.

Fisher, C. D. (1980). On the dubious wisdom of expecting job satisfaction to correlate with performance. Academy of Management Review, 5, 607-612.

Herman, J. B. (1973). Are situational contingencies limiting job attitude-job performance relationships? Organizational Behavior and Human Performance, 10, 208-224.

laffaldano, M. T., \& Muchinsky, P. M. (1985). Job satisfaction and job performance: A meta-analysis. Psychological Bulletin, 97, 251-273.

Isen, A. M., \& Means, B. (1983). The influence of positive affect on decision-making strategy. Social Cognition, 2, 18-31.

Jacobs, R., \& Solomon, T. (1977). Strategies for enhancing the prediction of job performance from job satisfaction.. Journal of Applied Psychology, 62, 417-421.

Johns, G. (1991). Substantive and methodological constraints on behavior and attitudes in organizational research. Organizational Behavior \& Human Decision Processes, 49, 80-104.

Judge, T. A., \& Hulin, C. L. (1993). Job satisfaction as a reflection of disposition: A multiple source causal analysis. Organizational Behavior and Human Decision Processes, 56, 388-421.

Judge, T. A., \& Watanabe, S. (1993). Another look at the job satisfaction^life satisfaction relationship. Journal of Applied Psychology, 78, 939-948. 
Katz, D., Maccoby, N., Gurin, G., \& Floor, L. G. (1951). Productivity, supervision, and morale among railroad workers. Ann Arbor: University of Michigan, Survey Research Center, Institute for Social Research.

Katz, D., Maccoby, N., \& Morse, N. C. (1950). Productivity, supervision, and morale in an office situation.. Ann Arbor: University of Michigan, Institute for Social Research.

Kahn, R., \& Katz, D. (1960). Leadership practices in relation to productivity and morale. In D. Cartwright \& A. Zander (Eds.), Group Dynamics: Research and Theory, $2^{\text {nd }}$ ed. Imsford, NY: Row, Paterson).

Kopelman, R. E., Brief, A. P., \& Guzzo, R. A. (1990). The role of climate and culture in productivity. In B. Schneider (Ed.), Organizational Climate and Culture (pp.282-318). San Francisco: Jossey-Bass.

Kornhauser, A., \& Sharp, A. (1932). Employee attitudes: Suggestions from a study a factory. Personnel Journal, 10, 393-401.

Koys, D. J. (2001). The effects of employee satisfaction, organizational citizenship behavior, and turnover on organizational effectiveness: A unit-level, longitudinal study. Personnel Psychology, 54, 101-114.

Lawler, E. E. (1973). Motivation in work organizations. Monterey, CA: Brooks/Cole. Lawshe, C. H., \& Nagle, B. F. (1953). Productivity and attitude toward supervision. Journal of Applied Psychology, 37, 159-162.

Lewis, C. A., \& Joseph, S. (1995). Convergent validity of the Depression-Happiness Scale with measures of happiness and satisfaction with life. Psychological Reports, 76, 876-878.

Locke, E. A., \& Latham, G. P. (1984). Goal-setting: A motivational technique that works! Englewood Cliffs, NJ: Prentice-Hall.

Lopez, E. M. (1982). A test of the self-consistency theory of the job performance-job satisfaction relationship. Academy of Management Journal, 25, 335-348.

McGreal R., \& Joseph, S. (1993). The Depression-Happiness Scale. Psychological Reports, 73, 1279-1282.

Moorman, R. H. (1993). The influence of cognitive and affective based job satisfaction measures on the relationship between satisfaction and organizational citizenship behavior. Human Relations, 46, 759-776.

Mowday, R. T., Steers, R. M., \& Porter, L. W. (1979). The measurement of organizational commitment. Journal of Vocational Behavior, 14, 224-247.

Organ, D. (1977). Inferences about trends in labor force satisfaction: A causalcorrelational analysis. Academy of Management Journal, 20, 510-519. 
Organ, D. W. (1988). Organizational citizenship behavior: The good soldier syndrome. Lexington, MA: Lexington Books.

Organ, D. W., \& Ryan, K. (1995). A meta-analytic review of attitudinal and dispositional predictors of organizational citizenship behavior. Personnel Psychology, 48, 775-802.

Petty, M. M., McGee, G. W., \& Cavender, J. W. (1984). A meta-analysis of the relationships between individual job satisfaction and individual performance. Academy of Management Review, 9, 712-721.

Podsakoff, P. M., Todor, W. D., \& Skov, R. (1982). Effects of leader contingent and noncontingent reward and punishment behaviors on subordinate performance and satisfaction. Academy of Management Journal, 25, 810-821.

Sherer, M., Maddux, J. E., Mercandante, B., Prentice-Dunn, S., Jacobs, B., \& Rogers, R. W. (1982). The self-efficacy scale: Construction and validation. Psychological Reports, 51, 663-671.

Smith, P.C., Kendall, L. M., \& Hulin, C. L. (1969). The measurement of satisfaction in work and retirement. Chicago: Rand McNally.

Smith, C. A., Organ, D. W., \& Near, J. P. (1983). Organizational citizenship behavior: Its nature and antecedents. Journal of Applied Psychology, 68, 653-663.

Staw, B.M. (1984). Organizational behavior: A review and reformulation of the field's outcome variables. Annual Review of Psychology, 35, 627-666.

Staw, B. M., Sutton, R. I., \& Pelled, L. H. (1994). Employee positive emotion and favorable outcomes at the workplace. Organization Science, 5, 51-68.

Tait, M., Padgett, M. Y., \& Baldwin, T. T. (1989). Job and life satisfaction: A reevaluation of the strength of the relationship and gender effects as a function of the date of the study. Journal of Applied Psychology, 74, 502-507.

Tett, R. P., \& Meyer, J. P. (1993). Job satisfaction, organizational commitment, turnover intention, and turnover: Path-analysis based on meta-analytic findings. Personnel Psychology, 46, 259-293.

Triandis, H. C. (1959). A critique and experimental design for the study of the relationship between productivity and job satisfaction. Psychological Bulletin, 56, 309312.

Vroom, V. H. (1964). Work and motivation. New York: Wiley.

Wright, T. A., \& Bonett, D. G. (1997). The role of pleasantness and activation-based well-being in performance prediction. Journal of Occupational Health Psychology, 2, 212-219. 
Wright, T. A., \& Cropanzano, R. (2000). Psychological well-being and job satisfaction as predictors of job performance. Journal of Occupational Health Psychology, 5, 84-94. 